Sintese - Rev. de Filosofia

V. 28 N. 92 (2001): 407-416

\title{
FILOSOFÍA Y POLÍTICA EN AMÉRICA LATINA
}

Ricardo Antoncich

CPAL - RJ

J. C. SCANNONE, V. SANTUC, Lo político en América Latina. Desafíos actuales. Contribución filosófica a un nuevo modo de hacer política, Buenos Aires, Bonum, 1999.

$\mathrm{P}$ ara quien desee tener una visión global de esta obra sería sufi ciente la lectura de la excelente introducción de J. C. Scannone, donde narra los procesos del equipo Jesuita latinoamericano de reflexión filosófica y sus sucesivas publicaciones desde 1992 hasta el presente. Sin embargo, enriqueciendo la perspectiva, que el proprio compilador señala como personal, quiero destacar la unidad de los temas comentando tres puntos indicados en el subtítulo de la obra: hacer política, de un nuevo modo, con una seria fundamentación filosófica. Los números se refieren a las páginas del libro.

\section{Hacer política...}

En toda la obra existe la convicción de que la política es un quehacer humano en un doble sentido, realizada por personas y como tarea de humanización. La herencia de la filosofía griega es pues evidente. Es acción práctica que tiene como objeto al proprio ser humano en esa tarea de descubrirse a si mismo que Vicente Santuc destaca muy bien (316; 
344-8). Los dos trabajos de M. E. M eza nos permiten evocar esas profundas raíces de la tradición del quehacer político. En el primero, Elementos para una antropología de lo político, se nos presenta al hombre como sujeto político ya desde la Grecia clásica. Lo político no es un proceso de individuos aislados que se unen para una acción sino el camino necesariamente social y político para realizar la "forma" de lo humano; no es por tanto una filosofía del individualismo sino del humanismo (61), tarea de todos que como demiurgos plasman en la realidad el ideal de lo político. El contraste con Kant, presentado por el mismo autor, sirve para destacar que lo que era un nomos de la naturaleza puede ser pensado con categorías modernas de un principio a priori de la razón práctica (66), oponiéndose en ambos casos a lo fenoménico de la experiencia dada. La tarea humana es configurar la materia de las máximas individuales marcadas por los intereses egoístas con la forma de universalidad que sólo la voluntad puede proporcionar y que conduce al respeto de la ley y a considerar a todo ser humano como fin en sí mismo. La sociedad humanizada es el reino de fines en sí, la comunidad humana del respeto y del crecimiento de la libertad. Para Kant, como para los griegos, estas antropologías tienen que transmitirse por la educación, que es elemento insustituible de la vida política. Por eso en su segundo trabajo, El papel de lo político en la construcción de una nación, Meza retorna a la experiencia clásica mostrando las condiciones casi únicas de la polis griega que permitieron unir el sentido de polis con el de nación. Se realizaba así aquel "plebiscito cotidiano" que implica el "sentirse un pueblo", como lo recuerda Gaete (444), y en el que la transmisión del ethos era la más fuerte razón de existir de la paideia.

\section{... de un modo nuevo...}

Hay estructuras que exigen ser renovadas por que el tiempo las ha vuelto obsoletas. Otras que están presionadas por nuevos desafíos, aunque todavía sean casi estrenadas. Nuestra democracia latinoamericana no tiene una larga práctica de siglos detrás, pero sí inéditos desafíos por delante. La globalización económica está "colonizando" otras esferas de convivencia humana y sometiéndolas a su imperio. Por eso es urgente rescatar la autonomía de lo político liberándolo de la servidumbre de los grandes intereses económicos. Hay cuatro trabajos de este libro que tratan de pensar en los modos nuevos del quehacer político. Meza, en el segundo artículo ya citado, nos presenta el desafío de reconstruir el tejido de valores e intereses comunes en un conjunto de naciones latinoamericanas que tuvieron las estructuras jurídicas como generadoras de las naciones. El sentido de pertenencia no se impone por decreto sino que se educa 0 se forma; de allí que los dos retos más importantes por asumir en las sociedades latinoamericanas sean el de definir la areté peculiar de cada nación y generar y cultivar en sus miembros un profundo sentido de pertenencia e identidad. 
El profesor Jorge Alonso, en Al encuentro de la democracia, destaca, en medio de los cambios conceptuales y reales de la democracia, la tarea de rescatar su esencia en particular ante tres grandes desafíos: hacerla garantía de los derechos humanos, respetuosa y configurada por los movimientos sociales y eficiente ante las demandas de la planetarización. Los desafíos son reales porque, si la voluntad popular de cada pueblo elige a sus gobernantes nacionales, esta decisión no afecta sólo al estado político sino en muchos casos la convivencia internacional. Qué decir, por ejemplo, de las tendencias racistas en algunos países europeos con sus políticas de exclusión racial y el reflorecimiento del nazismo como instrumento de exterminio de las "masas sobrantes"? Sabrán elegir las mayorías excluidas del tercer mundo a sus dirigentes en función de intereses a largo plazo para el crecimiento de la conciencia y de los valores nacionales o se dejarán "comprar" por ventajas a corto plazo que la globalización pueda proporcionarles para conseguir los líderes que más ventajas aseguren al sistema global? Serán los derechos humanos, y entre ellos el fundamental del derecho a la vida, garantizados por la democracia? Será la democracia el espacio de actores nuevos, de los movimientos sociales marginados y desarticulados por el imperialismo del dinero? La respuesta a estas preguntas las tenemos los seres humanos, pero no hay que olvidar que hay exigencias estructurales que están allí con sus posibilidades y condicionamientos.

Arturo Gaete, en Articulación de lo político con la sociedad civil en América Latina, recorre los cuatro grandes momentos vividos en el siglo XX: la aristocracia terrateniente, el desarrollo "hacia adentro", los regímenes militares y la transición a la democracia. Los conceptos fundamentales previos nos permiten comprender que el paso de la polis griega a los burgos medievales supone, entre otros aspectos, la evolución del trabajo hecho por esclavos a los artesanos libres y capaces de orientar sus intereses privados articulándolos con las decisiones públicas, primero de los señores feudales y después de los reyes y sucesivas de gobierno de las naciones. En este contexto se puede destacar la idea de Santuc de la importancia del trabajo humano para la modernidad, como el "nervio de toda la historia humana" (307) y verdadero espacio de sentido. El trabajo hecho no por esclavos sino por hombres y mujeres libres canaliza las aspiraciones y los intereses individuales y de ellas se teje la sociedad civil. Pero constituye un permanente desafío la articulación de los intereses privados con la búsqueda del bien común. Sin esta búsqueda, por parte de la sociedad civil, queda ésta sin parámetros para el control del ejercicio del poder en el Estado

La importancia de la educación ha sido registrada ya en algunos artículos mencionados, pero se vuelve tema central en el trabajo de J. R. Seibold Ciudadanía, transformación educativa e imaginario social urbano. No podemos entender la política sin referirla al bien común, pero a su vez, no entendemos este bien sin la referencia a los bienes particulares, a los que supone, pero a la vez, trasciende. Aun dentro de los valores parti- 
culares se impone muchas veces la opción por uno de ellos, la "preferencia" y por tanto la renuncia de unos en favor de otros. La sabiduría popular ha acuñado la frase "vale la pena" para indicar que hay pena porque hay renuncia, pero hay sentido por lo que "vale". El tema de los valores es pues eje de la articulación de los intereses personales y del bien común. Si tenemos, además, en cuenta el cruce de determinaciones del imaginario social, sobre todo el urbano de la mayoría de nuestras grandes ciudades - en las que se juegan muchas veces los destinos políticos - nos daremos cuenta de las tensiones y conflictos que se producen en el sentido de la identidad. Esto sucede por el cruce de lo tradicional, de lo moderno y de lo posmoderno, como sucede por ejemplo con el tipo de relaciones que los inmigrantes han heredado de sus orígenes campesinos (fiestas tradicionales, bailes regionales, etc.) y que les dan su sentido de pertenencia, mezclado con el tipo de relaciones del mundo del trabajo que les sitúa en el ámbito de la eficiencia y racionalidad de la modernidad, y al mismo tiempo manifestaciones del rechazo de esta misma modernidad, en búsqueda de sentido de justicia, el reconocimiento de derechos postergados, más propios de la posmodernidad. Es en el conjunto de todas estas situaciones en donde debe inculcarse el sentido de ciudadanía. Por eso la propuesta de Seibold es un énfasis muy fuerte en el papel de la escuela como ámbito privilegiado de formación de valores. La educación para la democracia supone un nuevo concepto de la educación para que se ejerciten ya desde la vida escolar las actitudes y valores de la vida ciudadana.

\section{... con una fundamentación filosófica.}

Lo que caracteriza las reflexiones hasta aquí presentadas no es por cierto la conciencia de la crisis que la globalización provoca en el ejercicio de la política, ni las aspiraciones o caminos para un modo nuevo de hacer política. Lo que los autores pretenden es un ejercicio crítico de reflexión filosófica. Se trata de ir a los fundamentos mismos de dicha acción. De buscar la lógica inherente a los actos políticos para que lleven a lo que parece ser un consenso humano: una mejor situación para todos.

La búsqueda de fundamentación sigue dos opciones bien características que separaron la filosofía de lo político clásica y moderna: lo nomotético y lo hipotético. Es decir, sostener el fundamento en las exigencias de una naturaleza normativa o encontrarlas en la hipótesis de un pacto social.

En la primera dirección se ubican los trabajos de Miguel Manzanera, Derecho, Política y Ética. Fundamentación en la filosofía de la nostridad; y de Juan Carlos Scannone: Lo social y político según Francisco Suárez. Hacia una relectura latinoamericana actual de la filosofía política de Suárez. Se hace evidente el caos futuro de una sociedad donde la economía globalizada no ha encontrado todavía cortapisas jurídicas. Por eso la búsqueda de un derecho universal, irrefutable, exigible para todos 
vuelve a colocarse como tema de la agenda del pensar filosófico. Situaciones más o menos parecidas como el descubrimiento de América llevaron a los teólogos, filósofos y juristas españoles a retomar el derecho natural y el ius gentium. Sin embargo, el positivismo jurídico consiguió imponerse en muchas partes, aunque no deja de ser interesante que algunos representantes del positivismo puro, como Kelsen y Radbruch, llegaran a revisas sus posiciones. Los esfuerzos contemporáneos por fundar un orden político a través de la cultura de la tolerancia que propone las Naciones Unidas, 0 de la ética del discurso de K. 0 . Apel 0 la ética mínima de Adela Cortina, no son suficientes porque desvinculan el derecho de la metafísica, por lo que Manzanera propone la vuelta al iusnaturalismo, pero con nueva fundamentación ética y antropológica en la filosofía de la nostridad ya presentada en otros libros del mismo equipo. La aceptación de la nostridad como el resultado del proceso dialéctico de la egoidad y de la alteridad, pero sin caer en los estrechos "nostrismos" que son egoísmos colectivos, sería un camino en la línea nomotética de fundamentación de la política. Manzanera nos recuerda que si la globalización es un hecho económico, también lo debe ser la globalización de lo jurídico.

La posición de Francisco Suárez, presentada por Scannone, une el camino nomotético con el hipotético, en el sentido de aceptar la tradicional fundamentación de lo político en la naturaleza humana, pero también destacar con vigor que esa naturaleza conduce a establecer actos libres de pactos sociales, como los de asociación, y en forma posterior, de forma de gobierno. Lo político aparece así mediado por la voluntad humana y de este modo Suárez se presenta como precursor de las corrientes modernas

El recurso al camino hipotético es claramente definido en el trabajo de A. Ocaña, Antropologías subyacentes en los conceptos políticos. En la línea de Hobbes, Marx, Freud o Levinas, se trata de una forma narrativa con comienzo y final, sin pretender que esta historia sea verdadera (125). En el caso de esta "historia ideal", se cuenta como primero lo más fundamental y como posterior lo derivado. Ocaña contrapone una narración hipotética de carácter filogenético (explicar la evolución de la especie humana). Su lema podría ser "tu libertad termina donde empieza la de los demás". El individuo surge como sujeto distinto de los objetos, pero el otro aparece como enemigo. Tal sería la situación inicial o el estado de naturaleza. El paso siguiente sería el reconocimiento del otro como un pacto, el cual necesita un garante con poder absoluto. Esta narración pretende explicar los valores individuales, pero también canaliza ya de una manera determinada la visión de lo político porque permite la identificación de estado y sociedad, la colonización de lo político por la economía, desvaloriza la autoridad y desconfía del poder y coloca la relación entre estados en términos de sometimiento o independencia. $\mathrm{Si}$ la libertad de uno (no importa si individuo o estado) termina donde empieza la de los demás se trata ante todo de fijar los límites por leyes 
y dar poder a un vigilante para que impida las transgresiones. El ideal de una autoridad mundial con poder coactivo (como podría pensarse de la ONU) se ha visto quebrado por la intervención de naciones poderosas que "a título personal" - por expresarlo de esta manera - han querido asumir el papel de árbitros del mundo.

Pero hay otro relato en la línea ontogenética, es decir que explica al ser personal. Un nuevo punto de partida, la persona como distinta del otro y éste otro que interpela un modo de ser: la persona responde por la com-veniencia en la Palabra para formar un nosotros radical. Si en la narración anterior el pacto consiste en ceder libertad para ganar seguridad, en esta narrativa se trata de pasar de la seguridad a la libertad, de hablar para decir algo nuevo y por tanto de pensar las reglas no como limitaciones sino como aquello que permite la expresión. Es verdad que respetar la palabra encierra también el riesgo de que el otro pueda decir "no" a la "com-veniencia" y al desear que el otro quede reducido en el nivel de pura naturaleza. Pero aquí la autoridad que vigila las irregularidades recupera el sentido proprio de autoridad que nos permite escuchar la voz que nos saca de la naturaleza para convenir en la cultura; la voz que, por tanto, nos hace crecer. La autoridad no consiste en "encerrar al violento transgresor" sino en abrirlo a la relación y hacerlo cada vez más libre. Es evidente que en esta narrativa todo recupera su sentido humano, y por tanto la sociedad prevalece sobre el estado, ya que el mayor abuso del poder del estado no es la corrupción sino el olvido de su deber de subsidiaridad. La economía vuelve a encontrar su lugar dentro de la política y ésta es pensada como ejercicio de la autoridad social que educa en los derechos humanos para un futuro mejor. Lo económico se vuelve en instrumento de la felicidad de todos. Es ésta narrativa una bella poesía llena de ingenuidades? Ocaña termina ofreciéndonos una apuesta, porque si en la primera narrativa hay casi una apuesta por el conflicto como base de relaciones humanas, también en la segunda la hay por la armonía. Si están iguales las posibilidades nada perdemos apostando por la solidaridad, sobre todo teniendo en cuenta que es más fácil destruir que construir; el interés egoísta separa y destruye, el amor solidario construye.

Si el conjunto de estos tres trabajos ejemplifican bien las opciones nomotéticas e hipotéticas, hay otros tres que tienen en común buscar inspiración para una fundamentación radical de lo político en tres pensadores contemporáneos: Zubiri, Lonergan y M erleau-Ponty. J. M. Dávalos estudia al primero en Lo político-social desde la filosofía de Zubiri, Gaspar Lo Biondo presenta Algunos elementos del aporte de Bernard Lonergan a la política, y finalmente V. Santuc se inspira claramente en el tercero para su trabajo Desde dónde mirar lo económico.

Para Zubiri la primera tarea es comprender "la realidad" sin establecer a priori el primado de la subjetividad consciente y del sentido, e incluso buscando algo más primordial que la comprensión del ser, que es lo que 
Zubiri llama "impresión de la realidad". La crítica zubiriana a la filosofía occidental es que se limitó a los contenidos aprehendidos (datos sensibles) sin atender a la formalidad que hace que dichos contenidos se revelen como independientes respecto a la aprehensión. La impresión de la realidad se realiza por la acción sentiente que comprende tres actos unidos entre sí en forma estructural, la aprehensión, la modificación tónica y la respuesta. La acción es pues la unidad estructurada de sensación, afección y volición. La originalidad del pensamiento zubiriano está en considerar la socialidad como un dato previo a todo lenguaje y compresión de sentido. La presencia de los otros está ya en mi sentir la realidad porque las cosas, y mucho más las personas, se me presentan como "otras" a mis actos de sensación, afección y volición con un "de suyo" que se me impone. Aparecen además como "entre" otras cosas y personas, abiertas unas a otras. Lo social y político no hacen sino evidenciar el modo humano de vivir en el mundo acogiendo la presencia de los demás y siendo conscientes de la realidad del poder. El poder, en Zubiri, es un momento de toda cosa real, es la "poderosidad".

Dávalos empalma el discurso zubiriano con el pensamiento de Hannah Arendt que considera el poder como nacido del vivir unido del pueblo. Este poder puede ser dominado por la fuerza que un solo hombre puede ejercer sobre sus semejantes. Mientras la fuerza es indivisible, el poder no lo es y por eso no se destruye ni disminuye al repartirse; por el contrario, el equilibrio de poderes hace crecer el mismo poder. La violencia puede destruir el poder pero no sustituirlo.

La importancia de la fundamentación zubiriana puede ser comprendida si atendemos a esfuerzos paralelos como el de González en Estructuras de la praxis, Madrid, Trotta, 1997, que considera dichas estructuras como una verdadera "filosofía primera" fundante de todo saber filosófico, y por tanto, tal vez un camino de certezas en el momento actual en el que ni la ciencia y técnica, ni las tradiciones morales o religiosas parecen ofrecer fundamentos para acciones que aseguren un futuro humano. El análisis de los actos, de su unidad en acción, de su transición a actuaciones y actividades, puede ofrecer, tal vez, un camino de fundamentación filosófica para la política.

Lo Biondo acude a Lonergan porque el pensamiento de éste permite la reflexión filosófica en juego con las ciencias sociales y por tanto de la praxis política. La "diferenciación de la conciencia" ha pasado de una primera fase (la revolución científica del siglo XVII hasta la primera Crítica de Kant) a su segunda hoy vigente que es evaluativa-afectiva en donde tiene cabida la racionalidad ético-comunicativa de la praxis. La tarea actual es rescatar la praxis que se encuentra, de algún modo, cautiva de la racionalidad técnica. La diferenciación de la conciencia permite poner la acción política como actividad libre y creadora de la conciencia humana, más orientada hacia los valores culturales de cualquier pueblo. Cuando se produce la convivencia humana hay ya una conciencia indiferenciada que se refleja en el autoconocimiento del sentido común; 
de allí se avanza hacia el campo de la interioridad y conciencia histórica; se toma conciencia así de una "intencionalidad consciente", la cual es presupuesto de toda conceptualización y por tanto de toda cultura política (284).

La libertad humana se juega no sólo en las decisiones políticas sino en múltiples opciones previas, como por ejemplo la apertura o la exclusión del horizonte religioso, que van a marcar dos posturas diferentes ante el problema del mal: o la opción por una hermenéutica de la sospecha o del amor gratuito. La opción por estas interpretaciones tiene mucha relevancia para la política, ya que una actitud de sospecha es peyorativa sobre la autenticidad de la conciencia, en tanto que la perspectiva del amor gratuito abre posibilidades sin desconfianza. Hay apertura para la cooperación y de esta manera se consigue el saber acumulativo y la distribución de tareas. Cuando la cooperación es reprimida o inexistente, la humanidad va en camino a la decadencia. Por el contrario, cuando la colaboración es estimulada, sobre todo por motivaciones trascendentes y religiosas, la capacidad de potenciar las fuerzas sociales es mucho mayor. Desde la práctica del amor gratuito es posible pensar en un modelo político que controle y fije los límites de los procesos económicos.

V. Santuc coloca el problema de la perspectiva del "desde donde" se miran los procesos, en nuestro caso, económicos. La historia de la filosofía ha presentado esos "desde donde" unificadores en lo subjetivo de la multiplicidad de datos que el mundo nos ofrece. Fueron los mitos, la religión, la filosofía y últimamente la ciencia. Fueron el punto de vista de un Dios exterior, Señor de la naturaleza y de la historia; o los productos de la conciencia con sus exigencias lógicas y sus evidencias; hace poco las lógicas internas de la historia, y en este momento el lenguaje "algoritmico" de la economía. La libertad del elegir, y sobre todo del elegirse a si mismo en su propia humanidad, parece quedar liberada de ese "miedo" que da todo ejercicio de la libertad, cuando alguien ajeno a nosotros nos dicta lo que debemos decidir y hacer. Hoy quien cumple esta función es la tecnociencia que se presenta como un saber limpio, transparente, riguroso, despojado de todo sentimiento y por tanto absolutamnente objetivo. La solución sería maravillosa si no fuese porque las evidencias nos dicen todo lo contrario. El progreso de la humanidad se concentra en pocos y deja desamparadas a las mayorías. Hoy no hay explotación de los pobres porque para ello sería necesario que "estuvieran" en un espacio asequible de relaciones laborales: hoy éstas no existen y los pobres ni siquiera son "dignos de ser explotados", pues simplemente "sobran", son sujetos inexistentes, excluidos.

El diagnóstico del problema es ciertamente descarnado, cruel, desesperante: es el "horror" que describe Viviana Forrestier. Las consecuencias de una razón que olvida que todos somos parte de un mismo mundo y compartimos un mismo don de vida, son trágicas. Por eso es urgente buscar un punto firme de apoyo, un "universal" innegable y unificador de toda la familia humana. Las múltiples teorías sociales y 
éticas se contraponen hasta el infinito y por cansancio nos urgen a pasar a otro nivel, a lo originario en nosotros, es decir a regresar a todo lo que es dado por igual a todos los hombres en su vida práctica. Es verdad que manejamos nuestra vida desde la conciencia en la relación sujeto y objeto, pero la percepción da algo pre-objetivo, en la sensibilidad de nuestro cuerpo: allí se dan las relaciones con los demás y el mundo: el cuerpo nos revela la dependencia de otro ser humano (allí está el ombligo) y de toda la naturaleza: nos revela que somos parte de un todo social y cósmico. Cuerpo hablante, porque primero escuchó las palabras de otros antes de proferir la propia. Antes de llegar al consenso en la verdad hay una revelación primera de nuestra participación con todos en un mismo mundo de la vida. La percepción nos revela en forma inmediata la coexistencia de las cosas y de los hombres; en este nivel todavía no se puede situar la tentación del dominio o de la exclusión, porque es el momento de la "fe perceptiva" que es la única capaz de dar sentido.

Para Santuc ese retorno a lo originario nos hace capaces de pronunciar nuevas palabras, nacidas de la autenticidad, y de comprender también la exigencias éticas y políticas. Cuando lo que hay que reformar no es el entendimiento humano sino el ser total humano, cuando lo que hay que adquirir es un ethos de la mortalidad que ofrezca a todos las razones para vivir y el sentido del morir, nos encontramos todos los miembros de la raza humana en la misma condición de sujetos en búsqueda. Lo único que nos puede orientar a todos es lo que todos tenemos en común, el hecho radical de ser "cuerpos hablantes" que marca nuestro lugar en el mundo para ir creando nuestra existencia con la palabra auténtica inseparable de la vida. Por eso debemos desconfiar de las abstracciones a las que puede llegar la razón, porque si de lo que se trata es de que la economía funcione (entendamos "esta economía" globalizada) nuestros oídos se volverán sordos a las muertes humanas que son el precio de ese funcionamiento. La vida pide que se revise el funcionamiento de la economía y no que ésta limite las condiciones de la vida.

Queremos formular algunas observaciones al conjunto de esta obra.

En primer lugar es un motivo de satisfacción que el pensar filosófico tome como objeto los temas de la ética, de la economía, de la política. Existe aquí la convicción de que la fundamentación crítica de todas esas disciplinas nos permite la interdisciplinariedad y el diálogo con las grandes corrientes del mundo contemporáneo.

También es un acierto que la fundamentación filosófica no se separe de las proyecciones, ya que son estas las que nos recuerdan los hechos concretos de la vida política: el preguntarnos por el sentido de la democracia hoy, por la inter-relación de estado y sociedad civil, por las exigencias de constituir el ethos de las naciones como base que sustente sus ideales políticos y por los valores de la vida democrática transmitidos por una educación actualizada en sus métodos y contenidos y muy 
consciente de la mezcla difusa de lo tradicional, de lo moderno y de lo posmoderno.

Sin embargo dado que el tema de lo político es un tema de todos los seres humanos, falta un proceso intermedio entre la profundidad filosófica y las exigencias de la práctica política inmediata. La asimilación de los aportes de Zubiri, Lonergan y Merleau-Ponty se dificultan al no filósofo por el escaso conocimiento de estas filosofías y no se ve cómo se puede pasar del lenguaje "indicativo" del fundamento a un lenguaje más "normativo" de lo que cada ciudadano debe hacer para poder fundar en sí mismo y en los demás su actuar político. La obligación moral de situarse en lo originario no aparece como una obligación universal de carácter jurídico y político. La misma crítica que se hace a pequeños espacios de creación de sentido, como pueden ser los microespacios de solidaridad (309), parece desalentar cualquier esfuerzo al nivel más asequible del individuo y su pequeño mundo por un cambio que puede llegar a lo macro social a través de redes cada vez más amplias de personas que son regidas por este valor.

Finalmente quiero hacer una observación que me parece pertinente respecto a Kant, dada la importancia que tiene en el pensamiento moderno y en fundamentaciones de la ética a partir de las condiciones a priori del discurso. Se observa con razón que Kant acaba con la metafísica al dar a las afirmaciones de la razón teórica sólo un valor fenoménico. Pero no se puede decir lo mismo respecto a la razón práctica, la cual, por definición, no puede encontrar obligación absoluta si no es por el acceso a lo noumenal, tanto en la comprensión de la libertad como condición de posibilidad, como en el carácter noumenal del respeto a la persona como fin en sí, y la consiguiente construcción de un ideal social y político en el reino de los fines en sí. Si ya no podemos hablar, como en la filosofía antigua de una metafísica que funda la ética y la política, sí debemos hablar de una ética y una política que nos abren para la metafísica.

Endereço do Autor:

Rua Marquês de Abrantes, 177 / 2201

22230-060 Rio de Janeiro - RJ

e-mail: ricardoan@cpalsj.org 